\section{Climate e-mails: man's mark is clear in thermometer record}

We welcome debate about the ethics of science prompted by the language of some of the hacked e-mails from the UK Climatic Research Unit (Nature 462, 545; 2009). Rightly or not, this has created concerns about the scientific process. But it is critical to point out that no grounds have arisen to doubt the validity of the thermometer-based temperature record since 1850 .

Both the detection of climate change and its attribution to human activities rely on the thermometer-based temperature record (compiled by the Climatic Research Unit and other institutions). They do not rely on proxy reconstructions of temperature over the past millennium, which are based on indirect evidence such as tree rings. Reconstructions contribute less to our understanding of climate than the thermometer record because of uncertainty both in these reconstructions and in the drivers of climate change before the twentieth century.

Unfortunately, the mainstream media have confused the two. The thermometer record shows unequivocally that Earth is warming, and provides the main evidence that this is caused by human activity. This crucial record remains unchallenged.

Commentators have suggested that the e-mails disclose a 'team mentality' among prominent climate scientists. Some people may have gone too far in promoting particular viewpoints, so an independent enquiry and open discussion should help to re-establish public confidence. However, it is absurd to suggest that there is some kind of global conspiracy involving all climate scientists.

We and our colleagues have worked with the scientists at the centre of this controversy. We have examined, used and at times criticized their data and results
- just as they, at times, have criticized ours. Our disagreements have no bearing on our respect for other aspects of their work.

Hans von Storch Institute for Coastal Research, 21502 Geesthacht, Germany e-mail: hvonstorch@web.de Myles Allen Department of Physics, University of Oxford, Oxford OX13PU, UK

\section{Climate e-mails: lack of data sharing is a real concern}

Your Editorial (Nature 462, 545; 2009) castigates "denialists" for making "endless, time-consuming demands for information under the US and UK Freedom of Information Acts". But you do not mention the reason - that the Climatic Research Unit at the University of East Anglia has systematically tried to avoid revealing data and code.

Science relies upon open analysis of data and methods, and the UK Natural Environment Research Council (NERC) has a clear data-sharing policy that expects scientists "to cooperate in validating and publishing [data] in their entirety". The university's leaked e-mails imply a concerted effort to avoid data sharing, which both violates the best practice defined in NERC policy and prevents verification of the results obtained by the unit. Asking for scientific data and code should not lead to anyone being branded as part of the "climate-changedenialist fringe".

David R. Bell Molecular Toxicology, School of Biology, University of Nottingham, Nottingham NG7 2RD, UK e-mail: david.bell@nottingham.ac.uk

\section{Step up aspirations to save biodiversity as 2010 begins}

The Convention on Biological Diversity's post-2010 targets are likely to aim for a halt in biodiversity loss by 2050 and for 'more modest' interim targets for 2020 (Nature 461, 1037; 2009).

Global aspirations need to be much higher than this to avert the accelerating and catastrophic decline in the variety of life forms on Earth.

A 2050 vision should aim both to arrest this loss and to restore the populations, habitats and ecological cycles that support biodiversity and ecosystem services. A 40-year horizon should be about right, given that the restoration of forests, wetlands, coral reefs and other habitats depends on species and processes that often have decades-long generational periods.

We should, at the very least, aim to maintain biodiversity and the health of ecosystems as they are now - in particular, by setting an intermediate target to prevent further extinctions.

The deadline for achieving 'more modest' targets should be 2015 , not 2020 . That would synchronise it with the Millennium Development Goals (J. D. Sachs et al. Science 325, 1502-1503; 2009) and with the timeframe of political cycles, which would help to ensure that elected politicians successfully deliver the target to their constituencies.

Ashok Khosla International Union for Conservation of Nature (IUCN), 22 Olaf Palme Marg,

New Delhi 110057, India

e-mail:president@iucn.org Julia Marton-Lefèvre IUCN Rue Mauverney 28, Gland 1196, Switzerland

\section{Icelandic genetic database not at risk from bankruptcy}

Although the Icelandic genomics company deCODE has filed for bankruptcy, this does not, as you put it in your News story (Nature 462, 401; 2009), leave the "fate of its valuable genetic database unclear".

As chief executive of deCODE, I can state that its Iceland-based subsidiary Islensk Erfdagreining continues to perform all of the company's human genetics work, managing its population resources, conducting its research and services, and processing its tests and genome scans.

It is Islensk Erfdagreining's scientists and laboratories that are licensed to undertake this work. We continue to operate under the same data and privacy protections as usual, rooted in the Icelandic community and within a tried and tested regulatory environment.

Nor should scientists be "lamenting the prospect of losing deCODE's vast database of genetic and medical information". Islensk Erfdagreining will probably be sold to another group of investors as a going concern. Such a change in ownership of the operating company will have no bearing on the terms under which Islensk Erfdagreining manages and analyses genetic samples and data.

Islensk Erfdagreining does not own these samples or the data. They are owned by the individuals who provide them and are only used for the specific purpose, whether research or testing, agreed upon with those individuals and under the regulatory protections under which we work.

These resources cannot therefore be sold and are not for sale. The genetics operation of Islensk Erfdagreining cannot be put in a box and dispatched elsewhere.

Kári Stefánsson deCODE genetics, Sturlugata 8, 101 Reykjavik, Iceland e-mail: kstefans@decode.is

Contributions may be submitted tocorrespondence@nature. com. Please refer to the Guide to Authors at go.nature.com/ cMCHno. They should be no longer than 300 words. Published contributions are edited. Science publishing issues are regularly featured at http://blogs.nature. com/nautilus, where we welcome comments and debate. 